\title{
Comparison of neoadjuvant therapy and upfront surgery in resectable pancreatic cancer: a meta-analysis and systematic review
}

This article was published in the following Dove Medical Press journal: OncoTargets and Therapy

\author{
Xiaohan Ren' \\ Xiyi Weil,* \\ Yichao Ding ${ }^{1, *}$ \\ Feng $\mathrm{Qi}^{2}$,* \\ Yundi Zhang' \\ Xin $\mathrm{Hu}^{\prime}$ \\ Chao Qin ${ }^{2}$ \\ Xiao $\mathrm{Li}^{3}$ \\ 'Department of First Clinical Medical \\ College of Nanjing Medical University, \\ Nanjing, Jiangsu 210009 , China; \\ 2Department of Urology, The First \\ Affiliated Hospital of Nanjing Medical \\ University, Nanjing, Jiangsu 210009 , \\ China; ${ }^{3}$ Department of Urology, \\ Jiangsu Institute of Cancer Research, \\ Affiliated Cancer Hospital of Nanjing \\ Medical University, Nanjing, Jiangsu \\ 210009, China \\ *These authors contributed equally \\ to this work
}

Objective: The role of neoadjuvant therapy (NAT) in resectable pancreatic cancer (RPC) remains controversial. Therefore, this meta-analysis was performed to compare the clinical differences between NAT and upfront surgery in RPC.

Materials and methods: A systematic literature search was performed in PubMed, Embase, Web of Science, and the Cochrane Register of Controlled Trials databases. Only patients with RPC who underwent tumor resection and received adjuvant or neoadjuvant treatment were enrolled. The OR or HR and 95\% CIs were calculated employing fixed-effects or random-effects models. The HR and its 95\% CI were extracted from each article that provided survival curve. Publication bias was estimated using funnel plots and Egger's regression test.

Results: In total, eleven studies were included with 9,386 patients. Of these patients, 2,508 (26.7\%) received NAT. For patients with RPC, NAT resulted in an increased R0 resection rate $(\mathrm{OR}=1.89 ; 95 \% \mathrm{CI}=1.26-2.83)$ and a reduced positive lymph node rate $(\mathrm{OR}=0.34$; 95\% $\mathrm{CI}=0.31-0.37$ ) compared with upfront surgery. Nevertheless, patients receiving NAT did not exhibit a significantly increased overall survival (OS) time ( $\mathrm{HR}=0.91 ; 95 \% \mathrm{CI}=0.79-1.05)$. Conclusion: In patients with RPC, R0 resection rate and positive lymph node rate after NAT were superior to those of patients with upfront surgery. The NAT group exhibited no significant effect on OS time when compared with the upfront surgery group. However, this conclusion requires more clinical evidence to improve its credibility.

Keywords: neoadjuvant therapy, resectable, pancreatic, neoplasm, prognosis, meta-analysis

\section{Introduction}

With an extremely poor prognosis and low resection rate, pancreatic cancer (PC) ranks the fourth most common cause of cancer-related deaths in the United States, and the fifth in Europe. ${ }^{1}$ PC starts when a cell in the pancreas gains genetic changes, allowing it to grow uncontrollably. Surgical resection is the only curative strategy for PC. For patients with localized disease, radical surgery may offer long-term benefits. ${ }^{2}$ However, even in patients who undergo resection, the 5-year survival rate remains only $7 \%-24 \%$, and the cumulative rate of recurrence remains up to $85 \%$, indicating that surgery alone is typically inadequate. ${ }^{3,4}$

For PC, the current standard of treatment is surgical resection with adjuvant chemotherapy. ${ }^{5,6}$ Some landmark experiments suggested the positive significance of adjuvant therapy. ${ }^{7,8}$ However, $20 \%-30 \%$ of patients failed to receive designated treatment due to postoperative complications, delayed recovery after surgery, patient rejection, comorbidities, or early disease recurrence, which is a major drawback of adjuvant therapy for PC. ${ }^{5,7,9}$ For borderline resectable PC, direct surgery may result in positive 
margins: R1 (microscopic margin) or R2 (positive margin). In recent years, neoadjuvant therapy (NAT) strategies have been increasingly employed for borderline resectable and resectable tumors. ${ }^{10-12}$ Previous studies demonstrated that NAT might improve the $\mathrm{R} 0$ (negative margin) resection rate and improve prognosis in borderline resectable PC (RPC). ${ }^{13,14}$

However, for RPC, no consensus has been achieved at present concerning whether it may improve the prognosis through NAT. Accordingly, we performed this study to compare the differences in overall survival (OS) time, R0 resection rate, and positive lymph nodes rate between patients who received NAT and those with upfront surgery.

\section{Materials and methods}

This meta-analysis followed the PRISMA guidelines. ${ }^{15}$

\section{Literature search}

The literature was reviewed systematically by searching PubMed, Embase, Web of Science, and the Cochrane Register of Controlled Trials databases from inception until September 2018. The search strategy in PubMed included the following domains of Medical Subject Heading terms: "pancreatic neoplasm", "neoadjuvant", and "resectable". These terms were combined with "AND" or "OR", which were provided in Table S2 (supporting information). Searched documents were not subject to publication time limitations. Embase, Web of Science, and Cochrane Library searches were completed with the authors' own terminology.

\section{Inclusion and exclusion criteria}

Studies included patients with RPC either treated by upfront surgery or NAT. Two authors independently assessed the included observational studies. Studies exclusion criteria were as follows: 1) patients without surgery were included in the study; 2) the study did not contain a control group; 3) for outcome indicators, the number of patients was unclear; and 4) the study included patients with marginally resectable or locally advanced PC.

\section{Data extraction and quality assessment}

Two authors independently evaluated the title and abstract of the primary selection and then conducted a full-text screening. Disagreements were resolved via discussion. $\mathrm{R} 0$ resection rate, positive lymph node rate, and survival data were extracted in each study. The HR and its 95\% CI were extracted from the survival curve provided in the article with Engauge Digitizer 4.1 software (Markmitch, Boston, MA, USA). ${ }^{16}$
Quality assessment of each article was performed using the Newcastle-Ottawa scale (NOS). ${ }^{17}$ The NOS allows for the evaluation of methods of patient selection, comparability of study groups, and reporting of important outcomes. Details are available in Table S1 (supporting information).

\section{Statistical analyses}

Analyses were performed using STATA version 12.0 (Stata Corporation, College Station, TX, USA) software. All $P$-values were two sided, and $P<0.05$ was regarded as significant. The results of individual studies were summarized. The estimates were calculated using fixed-effects or random-effects models according to the heterogeneity, which was reported using the Cochrane's $Q$-test ${ }^{18}$ and the inconsistency index value $\left(\mathrm{I}^{2}\right) .{ }^{19}$ Publication bias was judged using funnel plot and Egger's test.

\section{Results}

\section{Characteristics of included studies}

A total of eleven studies were included in the metaanalysis. ${ }^{20-30}$ The characteristics of the patients who received NAT and upfront surgery are presented in Tables 1 and 2, respectively. The upfront surgery group was regarded as the control group. Figure 1 presents the flowchart of the literature search and selection process. Age was the only available risk factor among the patients involved. However, no significant difference in age was observed between the NAT group and the upfront surgery group. The results of NOS analysis indicated that the studies we have included were of high quality.

\section{Meta-analysis results}

The main results of our meta-analysis are presented in Table 3. Eleven studies involving 9,388 patients were assessed in the comparison of the $\mathrm{R} 0$ resection rate. As indicated in Figure 2, patients receiving NAT before surgery had a better R0 resection rate compared with patients receiving upfront surgery (nine trials; 9,388 patients; $\mathrm{OR}=1.89 ; 95 \% \mathrm{CI}=1.26-2.83$ ), especially in the gemcitabine (Gem)-based + RT group (four trials; 757 patients; $\mathrm{OR}=3.59 ; 95 \% \mathrm{CI}=2.08-6.21)$. In the 5-fluorouracil (5-Fu)-based + RT group, the NAT group did not exhibit an obvious advantage (three trials; 487 patients; $\mathrm{OR}=1.36 ; 95 \% \mathrm{CI}=0.67-2.75)$. In the neoadjuvant chemotherapy (NCT) group, patients receiving chemotherapy had a higher $\mathrm{R} 0$ resection rate (two trials; 8,144 patients; $\mathrm{OR}=1.50$; 95\% CI=1.32-1.71).

Regarding the positive lymph node rate (Figure 3 ), the NAT group exhibited a remarkably reduced rate compared with the upfront surgery group (eleven trials; 9,386 patients; 
Table I Characteristics of the neoadjuvant treatment group included in the meta-analysis

\begin{tabular}{|c|c|c|c|c|c|c|c|c|c|}
\hline Reference & Year & \begin{tabular}{|l|} 
No. of \\
patients
\end{tabular} & $\begin{array}{l}\text { Median } \\
\text { age (years) }\end{array}$ & Regimen & $\begin{array}{l}\text { Median OS } \\
\text { (months) }\end{array}$ & $\begin{array}{l}\text { Resection } \\
\text { rate } \\
\text { ITT (\%) }\end{array}$ & \begin{tabular}{l|} 
R0 \\
rate \\
$(\%)$ \\
\end{tabular} & $\begin{array}{l}\text { Patients with } \\
\text { positive lymph } \\
\text { nodes }(\%)\end{array}$ & $\begin{array}{l}\text { Quality } \\
\text { score }\end{array}$ \\
\hline Fujii et $\mathrm{al}^{20}$ & 2017 & 40 & 65 & $\begin{array}{l}\text { 5-Fu + oteracil and } \\
\text { gimeracil + S- I + RT }\end{array}$ & 24.9 & 90 & 86 & 39 & 7 \\
\hline Mokdad et $\mathrm{al}^{21}$ & 2017 & 2,005 & 64 & $\mathrm{CT}$ & 26 & NM & 83 & 48 & 8 \\
\hline Casadei et $\mathrm{al}^{22}$ & 2015 & 18 & 71.5 & $\begin{array}{l}\text { Gem } 6 \text { weeks }+ \\
(\text { Gem }+ \text { RT) } 6 \text { weeks }\end{array}$ & NM & 61 & 64 & 55 & 7 \\
\hline Golcher et $\mathrm{al}^{23}$ & 2015 & 33 & 62.5 & $\begin{array}{l}\text { Gem + Cis + RT } \\
(55.8 \mathrm{~Gy})\end{array}$ & 25 & 58 & 90 & 32 & 8 \\
\hline Tzeng et $\mathrm{a}{ }^{24}$ & 2014 & 115 & 65.5 & $\mathrm{Gem}+\mathrm{Cis}+\mathrm{RT}$ & 28 & 82.6 & 89.4 & 51.6 & 7 \\
\hline Motoi et $\mathrm{a}^{25}$ & 2014 & 185 & 68 & $\begin{array}{l}\text { Gem/S-I/Gem + S-I/ } \\
\text { other/+ RT (35.2-54 Gy) }\end{array}$ & NM & 92.4 & 95.9 & 30.6 & 7 \\
\hline Papalezova et $\mathrm{a}^{26}$ & 2012 & 144 & 64 & $5-\mathrm{Fu}+\mathrm{RT}(30-50.4 \mathrm{~Gy})$ & 20 & 52 & 78 & 25 & 6 \\
\hline Tajima et $\mathrm{al}^{27}$ & 2012 & 13 & 62.6 & Gem + S-I & NM & NM & 84.6 & 76.9 & 6 \\
\hline Barbier et $\mathrm{a}^{28}$ & 2011 & 88 & 65 & 5-Fu + Cis + RT (45 Gy) & 17 & 43 & 74 & 29 & 7 \\
\hline Vento et $\mathrm{al}^{29}$ & 2007 & 22 & 65 & Gem + RT (50.4 Gy) & 30.2 & NM & NM & 32 & 7 \\
\hline Moutardier et $\mathrm{a}^{30}$ & 2004 & 39 & 65 & $5-\mathrm{Fu}+\mathrm{Cis}+\mathrm{RT}$ & 13.7 & 58 & NM & 13 & 7 \\
\hline
\end{tabular}

Abbreviations: Cis, cisplatin; 5-Fu, 5-fluorouracil; Gem, gemcitabine; ITT, intention to treat; NM, not mention; OS, overall survival; RT, radiation therapy; S-I, S-IMeiji Combination Capsules T20/T25; CT, chemotherapy.

$\mathrm{OR}=0.34 ; 95 \% \mathrm{CI}=0.31-0.37)$. In the subgroup analysis for positive lymph nodes, the Gem-based + RT group (five trials; 803 patients; OR=0.34; 95\% $\mathrm{CI}=0.25-0.47), 5-\mathrm{Fu}-$ based + RT group (four trials; 529 patients; OR $=0.22 ; 95 \%$ $\mathrm{CI}=0.14-0.33$ ), and the NCT group (two trials; 8,054 patients; $\mathrm{OR}=0.35 ; 95 \% \mathrm{CI}=0.31-0.38$ ) were associated with lower positive lymph node rates.

In the eleven studies included above, a total of seven studies (seven trials; 1,012 patients) provided either survival curves or HR and its $95 \%$ CI. The HR sum of survival for NAT compared with the upfront surgery group with a pooled
HR of $0.91(95 \% \mathrm{CI}=0.79-1.05)$ indicated no significant survival advantage for NAT. In the subgroup analysis for OS time (Figure 4), the Gem-based + RT group (three trials; 280 patients; $\mathrm{HR}=0.88 ; 95 \% \mathrm{CI}=0.69-1.12$ ) and the 5-Fu-based + RT group (four trials; 738 patients; $\mathrm{HR}=0.93$; 95\% CI $=0.78-1.11$ ) consistently exhibited insignificant advantages in OS time.

\section{Test of heterogeneity}

For the comparison of the $\mathrm{R} 0$ resection rate, moderate heterogeneity was observed. However, heterogeneity decreased

Table 2 Characteristics of the preoperative group included in the meta-analysis

\begin{tabular}{|c|c|c|c|c|c|c|c|}
\hline Reference & Year & $\begin{array}{l}\text { No. of } \\
\text { patients }\end{array}$ & $\begin{array}{l}\text { Median age } \\
\text { (years) }\end{array}$ & $\begin{array}{l}\text { Median OS } \\
\text { (months) }\end{array}$ & $\begin{array}{l}\text { Resection } \\
\text { rate } \\
\text { ITT (\%) }\end{array}$ & $\begin{array}{l}\text { R0 rate } \\
(\%)\end{array}$ & $\begin{array}{l}\text { Patients with } \\
\text { positive lymph } \\
\text { nodes (\%) }\end{array}$ \\
\hline Fujii et $\mathrm{al}^{20}$ & 2017 & 233 & 67 & 23.5 & 88 & 70 & 71 \\
\hline Mokdad et al ${ }^{21}$ & 2017 & 6,015 & 65 & 23 & NM & 76 & 74 \\
\hline Casadei et $\mathrm{a}^{22}$ & 2015 & 20 & 67.5 & NM & 75 & 33 & 87 \\
\hline Golcher et $\mathrm{al}^{23}$ & 2015 & 33 & 65.1 & 18.9 & 70 & 70 & 57 \\
\hline Tzeng et $\mathrm{a}^{24}$ & 2014 & 52 & 61.9 & 25.3 & 92.3 & 81.2 & 81 \\
\hline Motoi et $\mathrm{al}^{25}$ & 2014 & 397 & 68 & NM & 94.5 & 81.3 & 55.2 \\
\hline Papalezova et al ${ }^{26}$ & 2012 & 92 & 65 & 17 & 74 & 79 & 62 \\
\hline Tajima et $\mathrm{al}^{27}$ & 2012 & 21 & 66 & NM & NM & 85.7 & 54.1 \\
\hline Barbier et al ${ }^{28}$ & 2011 & 85 & 64 & 15 & 79 & 67 & 64 \\
\hline Vento et $\mathrm{al}^{29}$ & 2007 & 25 & 63 & 35.9 & NM & NM & 44 \\
\hline Moutardier et $\mathrm{al}^{30}$ & 2004 & 17 & 65 & 26.6 & 100 & NM & 65 \\
\hline
\end{tabular}

Abbreviations: ITT, intention to treat; NM, not mention; OS, overall survival. 


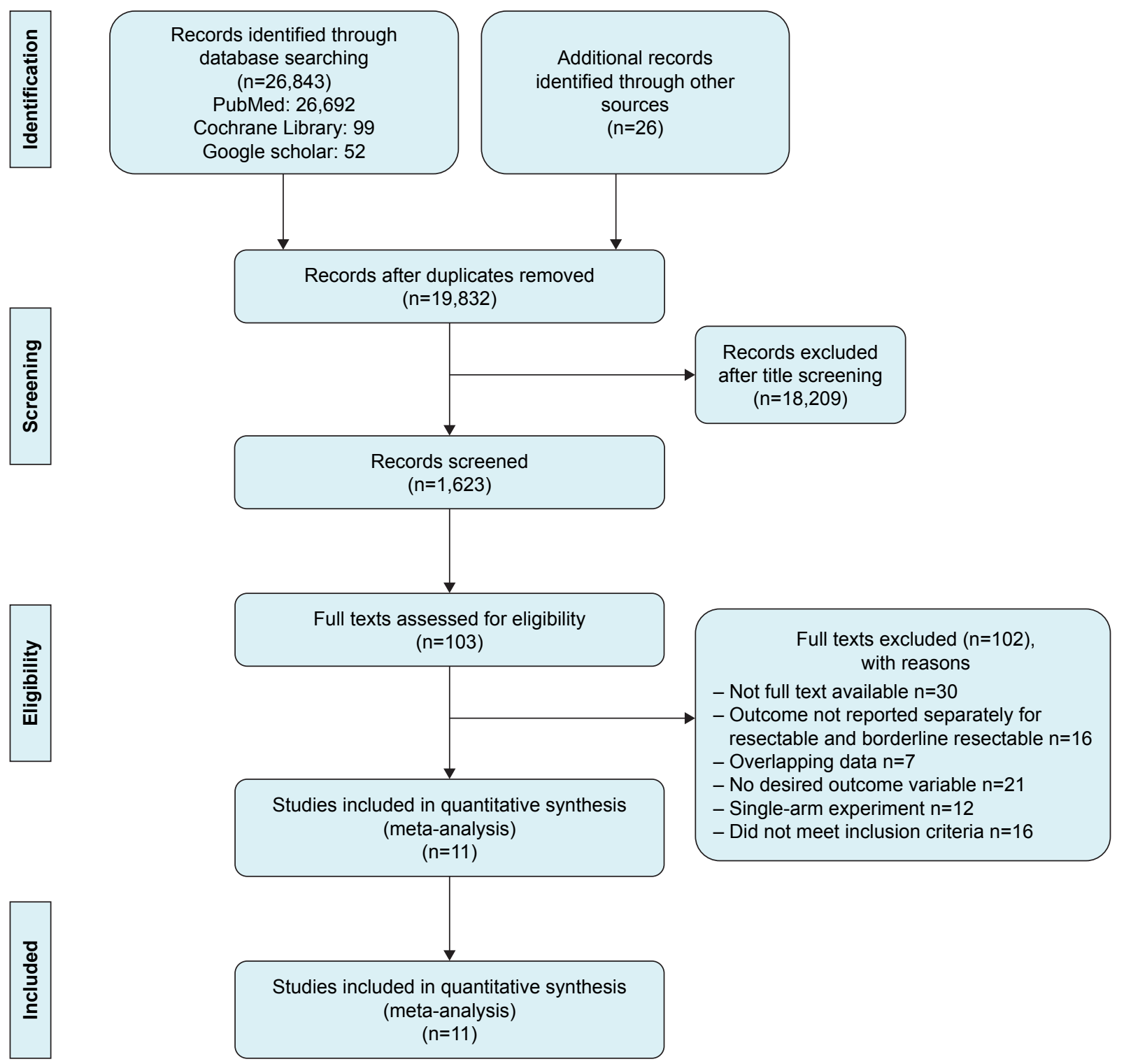

Figure I Flow diagram of literature search and selection process.

when subgroup analyses were conducted based on neoadjuvant treatment methods. In addition, no significant heterogeneity was observed in overall and subgroup comparisons for positive lymph node rate analysis and OS analysis.

\section{Sensitivity analysis}

Sensitivity analysis was utilized to detect the influence of each study by repeating the meta-analysis while omitting one study each time. Figures $5 \mathrm{~A}$ and $6 \mathrm{~A}$ revealed that the results were reliable given that no individual study affected the pooled OR or HR significantly.

\section{Publication bias}

Figure 5B indicates that no significant publication bias for the $\mathrm{R} 0$ resection rate was observed, and this finding was confirmed by Egger's test $(P=0.346)$. Moreover, the positive lymph node rate (Figure 7) did not exhibit publication bias (Egger's test: $P=0.122$ ). For the OS time comparison (Figure 6B), no significant publication bias was detected (Egger's test: $P=0.707$ ).

\section{Discussion}

PC is classified as resectable, marginally resectable, or locally advanced. ${ }^{31,32}$ However, to date, the only potentially curative technique for managing PC is surgical resection with radiotherapy and/or chemotherapy regimens, which may improve disease-free and OS time. ${ }^{33}$ At present, NAT is increasingly used in various types of PCs given its benefits for vascularization improvement, early treatment of micrometastasis, and potential downgrading effect on borderline resectable PC. ${ }^{34}$ 
Table 3 Meta-analysis results of noeadjuvant treatment for resectable pancreatic cancer

\begin{tabular}{|c|c|c|c|c|c|c|c|}
\hline Group & $\mathbf{N}^{\mathbf{a}}$ & Neoadjuvant $^{\mathrm{b}}$ & Surgery first ${ }^{c}$ & OR $(95 \% \mathrm{Cl})^{d}$ & $P$-value ${ }^{e}$ & HR $(95 \% \mathrm{Cl})^{d}$ & $P$-value ${ }^{e}$ \\
\hline \multicolumn{8}{|c|}{ R0 resection rate } \\
\hline Gem based + RT & 4 & 296 & 461 & $3.59(2.08-6.21)$ & 0.468 & - & - \\
\hline 5-Fu based $+\mathrm{RT}$ & 3 & 150 & 337 & $1.36(0.67-2.75)$ & 0.159 & - & - \\
\hline $\mathrm{CT}$ & 2 & 2,018 & 6,126 & $1.50(1.32-1.7 I)$ & 0.616 & - & - \\
\hline Total & 9 & 2,464 & 6,924 & $1.89(1.26-2.83)$ & 0.042 & - & - \\
\hline \multicolumn{8}{|c|}{ Positive lymph nodes } \\
\hline Gem based + RT & 5 & 317 & 486 & $0.34(0.25-0.47)$ & 0.757 & - & - \\
\hline 5-Fu based + RT & 4 & 173 & 356 & $0.22(0.14-0.33)$ & 0.617 & - & - \\
\hline $\mathrm{CT}$ & 2 & 2,018 & 6,036 & $0.35(0.3 \mathrm{I}-0.38)$ & 0.281 & - & - \\
\hline Total & 11 & 2,508 & 6,878 & $0.34(0.3 \mathrm{I}-0.37)$ & 0.610 & - & - \\
\hline \multicolumn{8}{|l|}{ Overall survival } \\
\hline Gem based + RT & 3 & 170 & 110 & - & - & $0.88(0.69-1.12)$ & 0.531 \\
\hline 5-Fu based $+\mathrm{RT}$ & 4 & 311 & 427 & - & - & $0.93(0.78-I . I I)$ & 0.324 \\
\hline Total & 7 & 481 & 531 & - & - & $0.91(0.79-1.05)$ & $0.56 \mathrm{I}$ \\
\hline
\end{tabular}

Notes: a Number of studies. 'Dumber of patients receiving neoadjuvant treatment. 'Number of patients receiving surgery first. ${ }^{\mathrm{C}} \mathrm{Random}$-effects model was used when $P$-value for heterogeneity test $<0.1$; otherwise, fixed-effects model was used. eP-value of $Q$ test for heterogeneity.

Abbreviations: 5-Fu, 5-fluorouracil; Gem, gemcitabine; RT, radiation therapy; CT, chemotherapy.

Some previous analyses of PC revealed that patients receiving NAT exhibited a longer survival time. ${ }^{35,36}$ However, most of these studies only analyzed marginal resectable or locally advanced PC, which exhibited a poor prognosis if only upfront surgery treatment was administered. NAT is considered safe for resectable $\mathrm{PC},{ }^{37}$ and neoadjuvant therapy with multiple drugs is usually superior to monotherapy. ${ }^{38}$ Thus, new adjuvant therapies are increasingly being applied for RPC. The transition from upfront surgical to a systemic approach in the form of NAT is being investigated for the treatment of
RPC. ${ }^{39,40}$ The driving force behind this shift is the growing recognition of the systematic early origins of the disease. ${ }^{41}$ However, previous studies on NAT for RPC were limited, and the results were inconclusive. For example, one study reported no difference in OS time between the NAT group and the upfront surgery group. ${ }^{42}$ However, some studies demonstrated that the survival rate of the NAT group was significantly improved compared with the upfront surgery group. ${ }^{21,30}$

Meta-analysis can provide more reliable results compared with a single study and serves as a powerful tool to explain

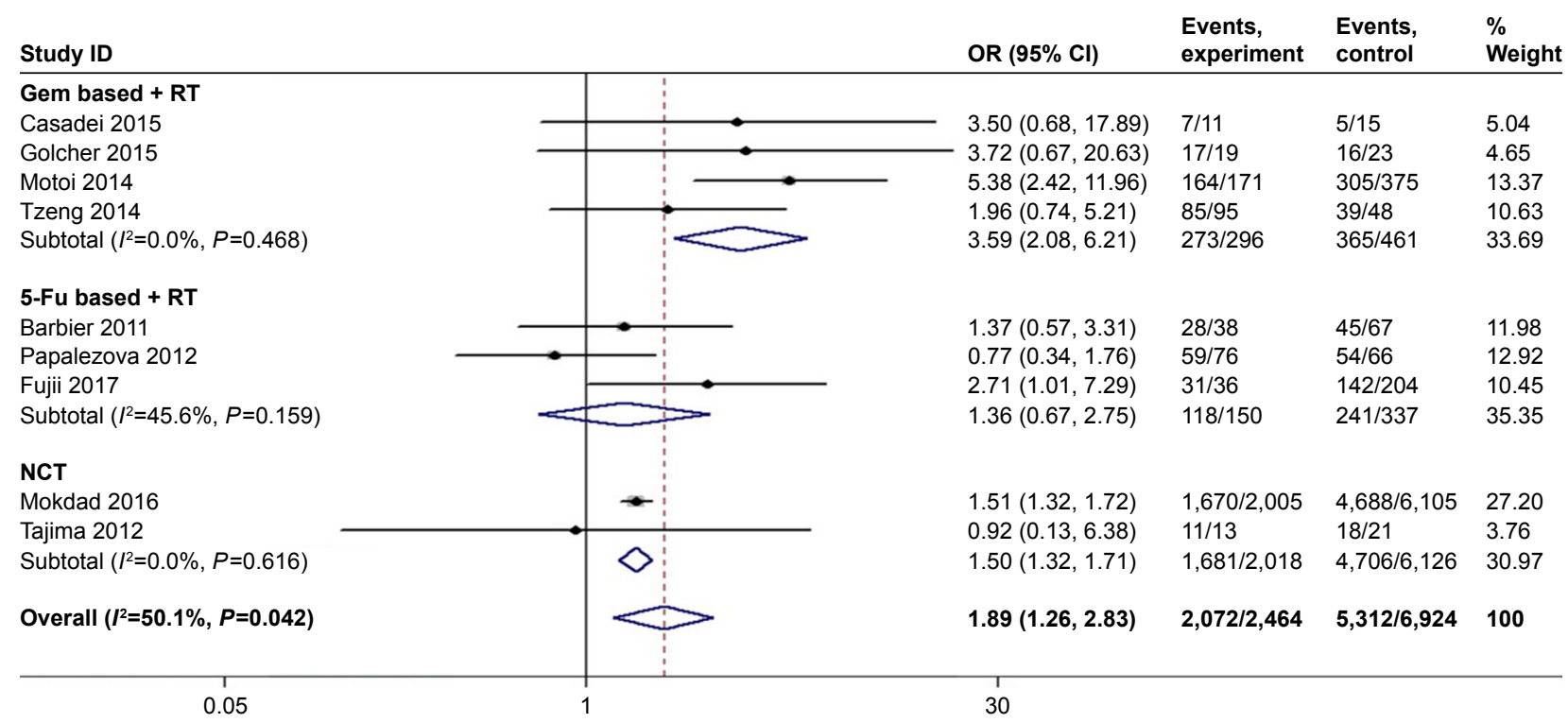

Figure 2 Forest plots of R0 resection rate.

Note: Weights are from random-effects analysis.

Abbreviations: 5-Fu, 5-fluorouracil; Gem, gemcitabine; NCT, neoadjuvant chemotherapy; RT, radiation therapy. 


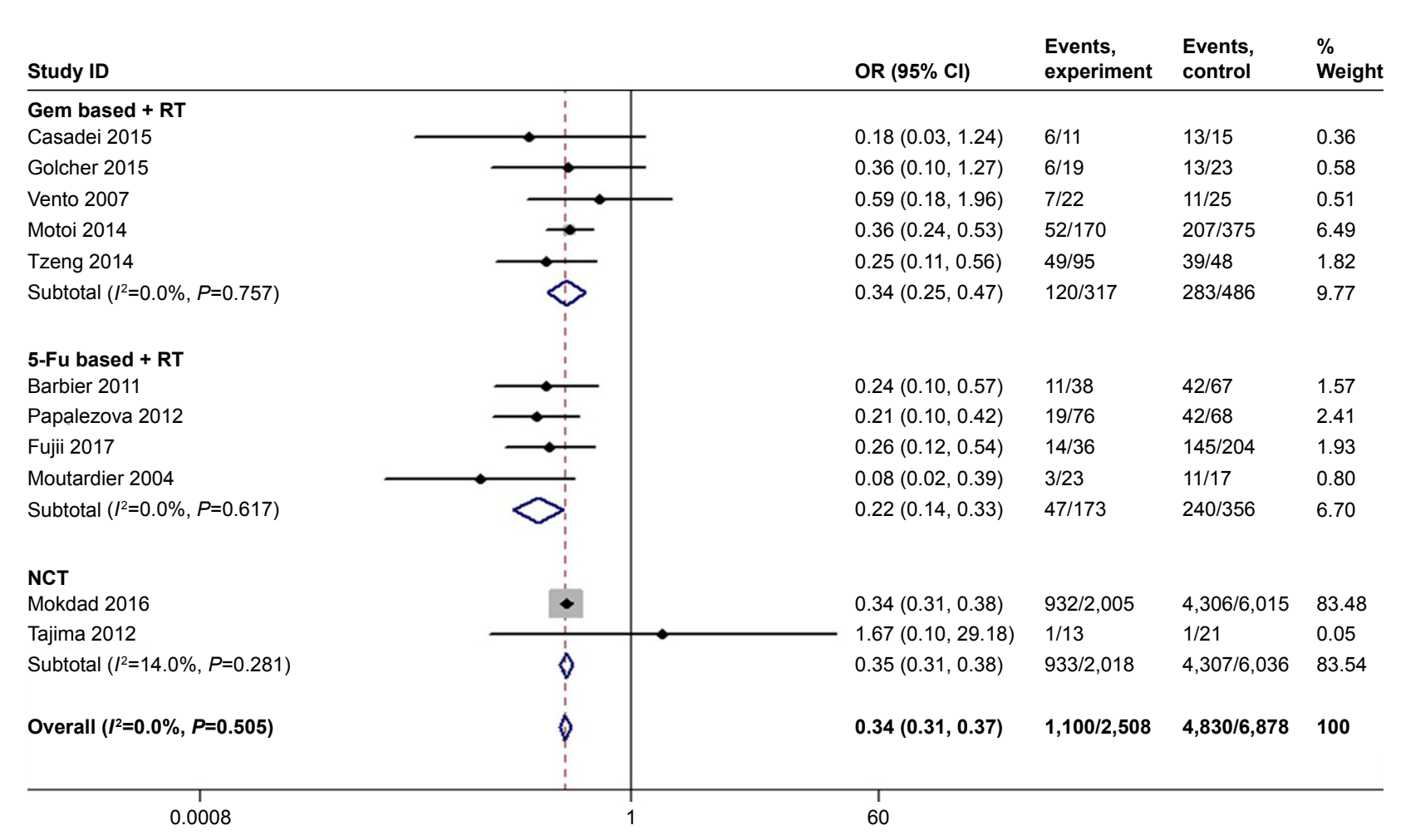

Figure 3 Forest plots of positive lymph nodes.

Abbreviations: 5-Fu, 5-fluorouracil; Gem, gemcitabine; NCT, neoadjuvant chemotherapy; OS, overall survival; RT, radiation therapy.

controversial conclusions. For this reason, we performed a meta-analysis to clarify whether NAT has significant benefits for RPC compared with upfront surgery. This meta-analysis was not the first meta-analysis that focused on the effect of NAT on RPC. However, we included newer and higherquality studies and obtained a larger sample size to arrive at a more accurate conclusion. As a result, the comparative analysis between the NAT group and upfront surgery group revealed that NAT played a positive role on $\mathrm{R} 0$ resection rate and positive lymph node rate. This finding was consistent with our expectations. ${ }^{35,43}$ However, the benefits of NAT for OS time were statistically insignificant. In the studies we

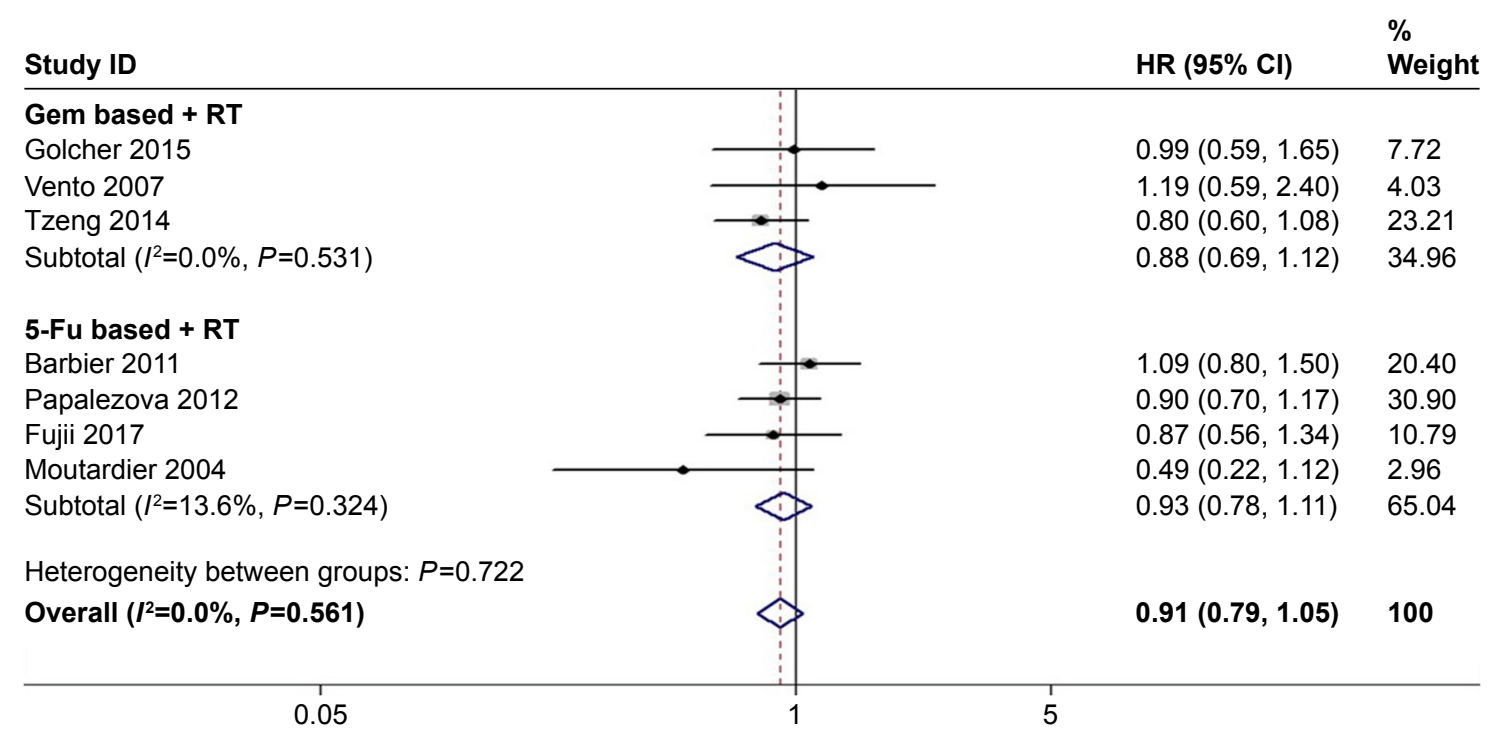

Figure 4 Forest plots of OS time.

Abbreviations: 5-Fu, 5-fluorouracil; Gem, gemcitabine; OS, overall survival; RT, radiation therapy. 


\section{A}

Meta-analysis estimates, given named study is omitted

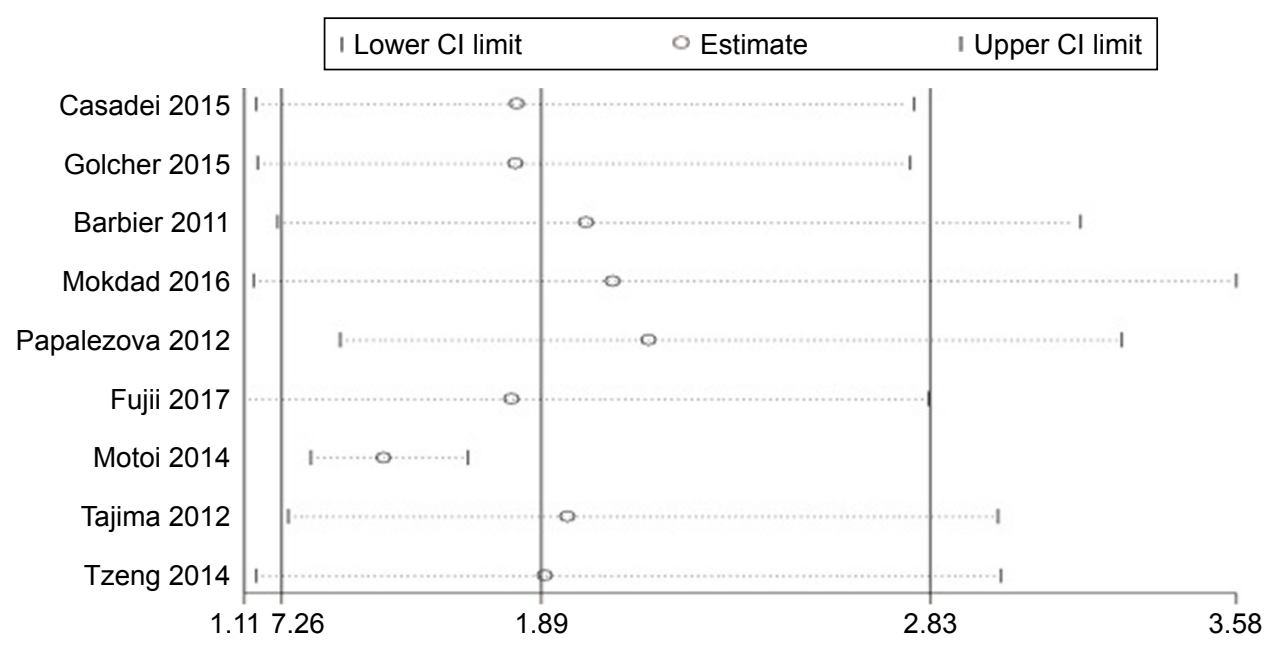

\section{B}

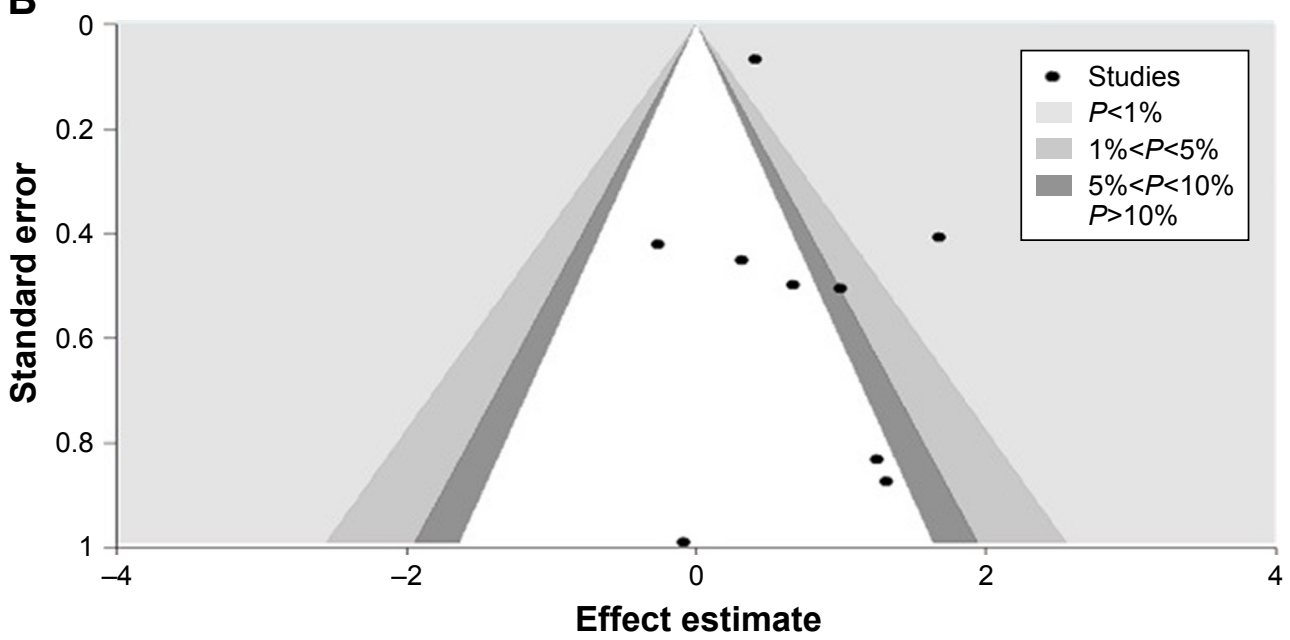

Figure 5 Sensitivity analysis and funnel plot of the R0 resection rate.

Notes: (A) Sensitivity analysis of the R0 resection rate. (B) Funnel plot of the R0 resection rate.

included, $73.6 \%$ of the patients who were judged resectable were resected after NAT. This rate was similar to published resection rates of $78 \%-96 \%{ }^{44}$

Currently, various NAT methods have been used in clinical practice. ${ }^{20-30}$ Most studies supported the use of Gem or 5-Fu in the neoadjuvant setting. In fact, different neoadjuvant settings may lead to different clinical outcomes, suggesting that the prognostic indicators of PC can vary notably due to methodological differences. As a result, stratified analysis was performed based on neoadjuvant therapy methods. Regarding the R0 resection rate, the NCT group without radiation therapy also had a higher $\mathrm{R} 0$ resection rate, indicating the significant role of chemotherapy drugs in resectable PC. In fact, for resectable PC, neoadjuvant radiotherapy has often been used in conjunction with chemotherapy to improve marginal negative resection rates. ${ }^{45}$ In the subgroup analysis with radiation therapy, the Gem-based + RT group exhibited more advantages compared with the 5-Fu-based + RT group. There are several possible mechanisms to explain this result. First, Gem has potent radiosensitizing properties that are critical in a disease with a propensity for positive surgical margins and local recurrence. ${ }^{46}$ Second, compared with $5-\mathrm{Fu}$, the use of $\mathrm{Gem}$ as a radiosensitizer generates greater tumor cell killing. Moreover, Gem provides superior systemic treatment of micrometastases. ${ }^{10}$

After surgical resection, $\sim 80 \%$ of patients exhibited a potential risk of extrapancreatic metastasis and required adjuvant therapy. Indeed, the surgical approach and postoperative 
A

Meta-analysis estimates, given named study is omitted
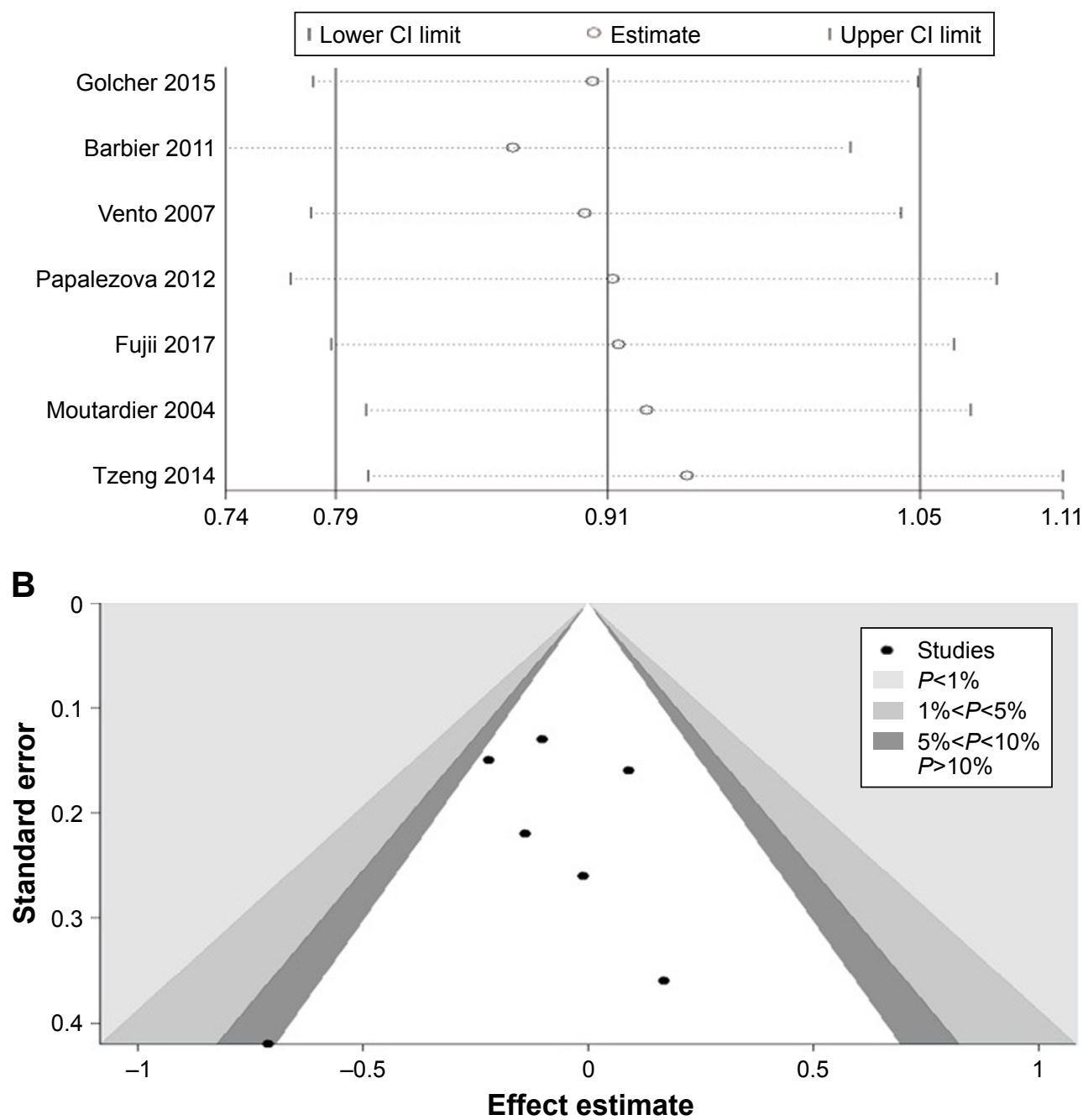

Figure 6 Sensitivity analysis and funnel plot of OS.

Notes: (A) Sensitivity analysis of OS. (B) Funnel plot of OS.

Abbreviation: OS, overall survival.

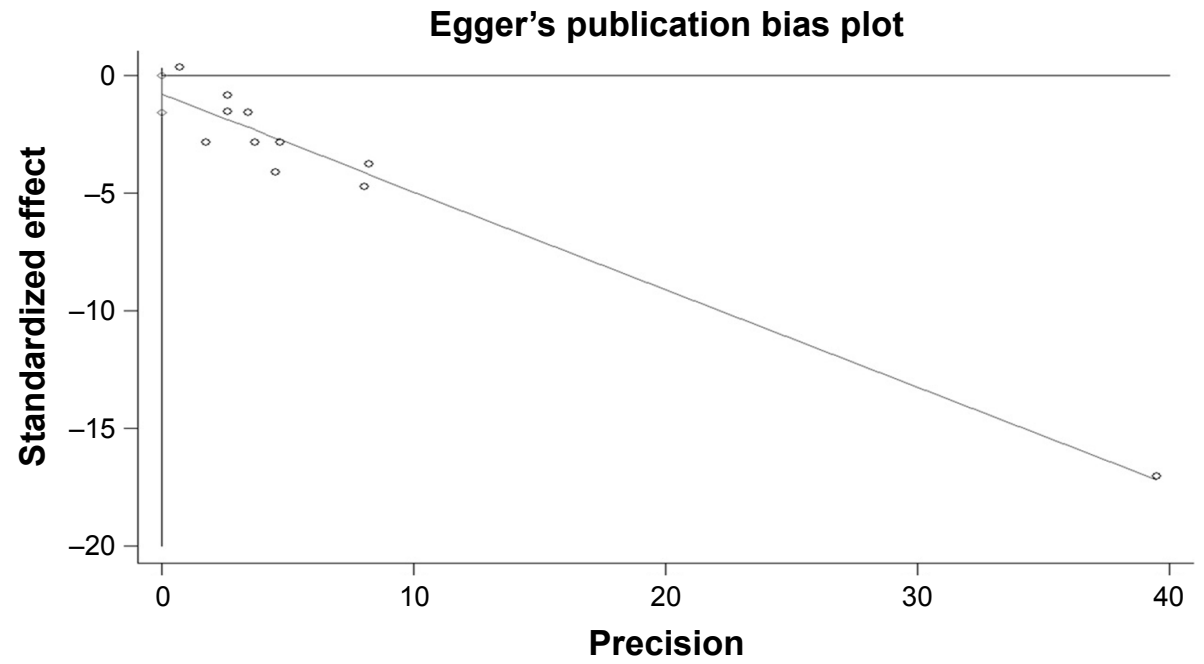

Figure 7 Egger's funnel plot for publication bias test of positive lymph nodes. 
recovery process may lead to a delayed or reduced dose of radiotherapy and chemotherapy, thus objectively delaying adjuvant therapy. Previous studies demonstrated that NAT may lead to a more favorable regression of lymph node metastasis compared with adjuvant therapy. ${ }^{47}$ At the time of surgery, patients who received NAT had smaller tumor sizes. Although the specific mechanism is unclear, the positive lymph node rate was significantly reduced in the NAT group in most studies. ${ }^{20,21,23}$ The results of our study were consistent with previous studies, which further showed that NAT played an important role in positive lymph nodes. For RPC, neoadjuvant chemoradiation may exhibit a reduced positive lymph node rate compared with neoadjuvant chemotherapy, and the addition of radiation therapy may improve the quality of NAT. ${ }^{48}$ However, further studies are needed to determine whether the difference is statistically significant. Moreover, the addition of radiotherapy may increase costs. ${ }^{48}$

Overall, survival time is one of the most prognostic indicators for survival in RPC patients. Differences in neoadjuvant settings exhibit different impacts on prognosis. Finally, the results of our meta-analysis for RPC demonstrated similar OS values for the Gem-based + RT group and 5-Fu-based + RT group compared to the upfront surgery group. These effects may be attributed to several possible mechanisms. First, compared with marginal resectable or locally advanced PC, RPC exhibits better tissue and cell characteristics, which may explain why NAT did not have significant benefits for RPC. In addition, patients exclusively treated with upfront surgery generally received additional adjuvant therapy at a later date. However, a small number of patients refused to receive adjuvant therapy or terminated it ahead of schedule for various reasons, which may make the associations unreliable.

Furthermore, despite the overall robust statistical evidence generated through this analysis, some limitations have been identified. First, among the studies we included, only three studies were randomized controlled trials with a total of 165 patients. Currently, the number of completed RCT is insufficient, which may be due to the slow recruitment of patients and patient choice. Moreover, it is difficult for multicenter experimental institutions to reach a unified opinion given the diversity of neoadjuvant treatment options. As a result, the small number of RCT studies is inevitable to some extent. Therefore, more studies are required to provide more clear conclusions. Second, in addition to age, other information about the included population, such as gender and lifestyle, was not available in most studies. Moreover, as a multifactorial disease, $\mathrm{PC}$ results from a combination of various complicated factors, including a variety of genetic and environmental factors. Therefore, if all patient data had been available, the results would have been more accurate.

\section{Conclusion}

The results of the present meta-analysis suggested that NAT can increase the $\mathrm{R} 0$ resection rate and decrease the positive lymph node rate. However, patients receiving NAT exhibited comparable survival as patients receiving upfront surgery. These results indicate that NAT offers insignificant advantages for postoperative survival. Although upfront surgery continues to be the standard and only curative treatment option for RPC, the results of this meta-analysis demonstrate the increasing use of NAT with some favorable outcomes. Numerous RCT studies are ongoing, for example, the NCT01372735. ${ }^{49}$ These studies focus on RPC and its prognosis after receiving NAT. We believe that when these studies are completed, we will draw more accurate conclusions after analyzing their data.

\section{Disclosure}

The authors report no conflicts of interest in this work.

\section{References}

1. Siegel RL, Miller KD, Jemal A. Cancer statistics. CA Cancer J Clin. 2018 ; 65(1):7-30.

2. Schmidt CM, Turrini O, Parikh P, et al. Effect of hospital volume, surgeon experience, and surgeon volume on patient outcomes after pancreaticoduodenectomy: a single-institution experience. Arch Surg. 2010;145(7):634-640.

3. National Cancer Institute Surveillance, Epidemiology and End Results Program SEER Stat Fact Sheets. Pancreas cancer. Available from: http:// seer.cancer.gov/statfacts/html/pancreas.html. Accessed July 13, 2016

4. Miller KD, Siegel RL, Lin CC, et al. Cancer treatment and survivorship statistics, 2016. CA Cancer J Clin. 2016;66(4):271-289.

5. Oettle H, Neuhaus P, Hochhaus A, et al. Adjuvant chemotherapy with gemcitabine and long-term outcomes among patients with resected pancreatic cancer: the CONKO-001 randomized trial. JAMA. 2013;310(14): 1473-1481.

6. Heestand GM, Murphy JD, Lowy AM. Approach to patients with pancreatic cancer without detectable metastases. J Clin Oncol. 2015; 33(16):1770-1778.

7. Neoptolemos JP, Stocken DD, Friess H, et al. A randomized trial of chemoradiotherapy and chemotherapy after resection of pancreatic cancer. N Engl J Med. 2004;350(12):1200-1210.

8. Maeda A, Boku N, Fukutomi A, et al. Randomized phase III trial of adjuvant chemotherapy with gemcitabine versus S-1 in patients with resected pancreatic cancer: Japan Adjuvant Study Group of Pancreatic Cancer (JASPAC-01). Jpn J Clin Oncol. 2008;38(3):227-229.

9. Neoptolemos JP, Dunn JA, Stocken DD, et al. Adjuvant chemoradiotherapy and chemotherapy in resectable pancreatic cancer: a randomised controlled trial. Lancet. 2001;358(9293):1576-1585.

10. Isaji S, Mizuno S, Windsor JA, et al. International consensus on definition and criteria of borderline resectable pancreatic ductal adenocarcinoma 2017. Pancreatology. 2018;18(1):2-11.

11. Jang JY, Han Y, Lee H, et al. Oncological benefits of neoadjuvant chemoradiation with gemcitabine versus upfront surgery in patients with borderline resectable pancreatic cancer: a prospective, randomized, open-label, multicenter phase 2/3 trial. Ann Surg. 2018;268(2) 215-222. 
12. Varadhachary GR, Wolff RA, Crane CH, et al. Preoperative gemcitabine and cisplatin followed by gemcitabine-based chemoradiation for resectable adenocarcinoma of the pancreatic head. J Clin Oncol. 2008;26(21):3487-3495.

13. Sutton JM, Abbott DE. Neoadjuvant therapy for pancreas cancer: past lessons and future therapies. World J Gastroenterol. 2014;20(42): 15564-15579.

14. Heinrich S, Pestalozzi BC, Schäfer M, et al. Prospective phase II trial of neoadjuvant chemotherapy with gemcitabine and cisplatin for resectable adenocarcinoma of the pancreatic head. J Clin Oncol. 2008; 26(15):2526-2531.

15. Moher D, Liberati A, Tetzlaff J, Altman DG; The PRISMA Group. Preferred reporting items for systematic reviews and meta-analyses: the PRISMA statement. PLoS Med. 2009;6(7):e1000097.

16. Tierney JF, Stewart LA, Ghersi D, Burdett S, Sydes MR. Practical methods for incorporating summary time-to-event data into meta-analysis. Trials. 2007;8(1):16.

17. Wells G, Shea B, O'Connell D, et al [webpage on the Internet]. The Newcastle-Ottawa scale (NOS) for assessing the quality if nonrandomized studies in meta-analyses. Available from: http://www.ohri.ca/ programs/clinical_epidemiology/oxford.asp. Accessed March 15, 2018.

18. Lau J, Ioannidis JP, Schmid CH. Quantitative synthesis in systematic reviews. Ann Intern Med. 1997;127(9):820-826.

19. Higgins JP, Thompson SG, Deeks JJ, Altman DG. Measuring inconsistency in meta-analyses. BMJ. 2003;327(7414):557-560.

20. Fujii T, Satoi S, Yamada S, et al. Clinical benefits of neoadjuvant chemoradiotherapy for adenocarcinoma of the pancreatic head: an observational study using inverse probability of treatment weighting. J Gastroenterol. 2017;52(1):81-93.

21. Mokdad AA, Minter RM, Zhu H, et al. Neoadjuvant therapy followed by resection versus upfront resection for resectable pancreatic cancer: a propensity score matched analysis. J Clin Oncol. 2017;35(5):515-522.

22. Casadei R, Di Marco M, Ricci C, et al. Neoadjuvant chemoradiotherapy and surgery versus surgery alone in resectable pancreatic cancer: a single-center prospective, randomized, controlled trial which failed to achieve Accrual targets. J Gastrointest Surg. 2015;19(10):1802-1812.

23. Golcher H, Brunner TB, Witzigmann H, Marti L. Neoadjuvant chemoradiation therapy with gemcitabine/cisplatin and surgery versus immediate surgery in resectable pancreatic cancer: results of the first prospective randomized phase II trial. Strahlenther Onkol. 2015;191:7-16.

24. Tzeng CW, Tran Cao HS, Lee JE, et al. Treatment sequencing for resectable pancreatic cancer: influence of early metastases and surgical complications on multimodality therapy completion and survival. J Gastrointest Surg. 2014;18(1):16-25.

25. Motoi F, Unno M, Takahashi H, et al. Influence of preoperative anticancer therapy on resectability and perioperative outcomes in patients with pancreatic cancer: Project Study by the Japanese Society of Hepato-Biliary-Pancreatic Surgery. J Hepatobiliary Pancreat Sci. 2014; 21(2):148-158.

26. Papalezova KT, Tyler DS, Blazer DG, et al. Does preoperative therapy optimize outcomes in patients with resectable pancreatic cancer? J Surg Oncol. 2012;106(1):111-118.

27. Tajima H, Ohta T, Kitagawa H, et al. Pilot study of neoadjuvant chemotherapy with gemcitabine and oral S-1 for resectable pancreatic cancer. Exp Ther Med. 2012;3(5):787-792.

28. Barbier L, Turrini O, Grégoire E, Viret F, Le Treut YP, Delpero JR. Pancreatic head resectable adenocarcinoma: preoperative chemoradiation improves local control but does not affect survival. HPB. 2011; 13(1):64-69.

29. Vento P, Mustonen H, Joensuu T, Kärkkäinen P, Kivilaakso E, Kiviluoto T. Impact of preoperative chemoradiotherapy on survival in patients with resectable pancreatic cancer. World J Gastroenterol. 2007;13(21):2945-2951.

30. Moutardier V, Turrini O, Huiart L, et al. A reappraisal of preoperative chemoradiation for localized pancreatic head ductal adenocarcinoma in a 5-year single-institution experience. J Gastrointest Surg. 2004; $8(4): 502-510$
31. Steliarova-Foucher E, Stiller C, Lacour B, Kaatsch P. International Classification of Childhood Cancer, third edition. Cancer. 2005;103(7): 1457-1467.

32. Fritz A, Percy C, Jack A. International Classification of Diseases for Oncology. 3rd ed. Geneva: World Health Organization; 2000.

33. National Comprehensive Cancer Network, NCCN Guideline: Pancreatic Adenocarcinoma. Version 1.2019. Available from: https://www. nccn.org/professionals/physician_gls/pdf/pancreatic.pdf. Accessed September 1, 2019.

34. Artinyan A, Anaya DA, McKenzie S, Ellenhorn JD, Kim J. Neoadjuvant therapy is associated with improved survival in resectable pancreatic adenocarcinoma. Cancer. 2011;117(10):2044-2049.

35. Versteijne E, Vogel JA, Besselink MG, et al. Meta-analysis comparing upfront surgery with neoadjuvant treatment in patients with resectable or borderline resectable pancreatic cancer. Br J Surg. 2018;105(8): 946-958.

36. Sultana A, Tudur Smith C, Cunningham D, Starling N, Neoptolemos JP, Ghaneh P. Meta-analyses of chemotherapy for locally advanced and metastatic pancreatic cancer: results of secondary end points analyses. Br J Cancer. 2008;99(1):6-13.

37. Heinrich S, Schäfer M, Weber A, et al. Neoadjuvant chemotherapy generates a significant tumor response in resectable pancreatic cancer without increasing morbidity. Ann Surg. 2008;248(6):1014-1022.

38. Palmer DH, Stocken DD, Hewitt H, et al. A randomized phase 2 trial of neoadjuvant chemotherapy in resectable pancreatic cancer: gemcitabine alone versus gemcitabine combined with cisplatin. Ann Surg Oncol. 2007;14(7):2088-2096.

39. Tempero MA, Malafa MP, Behrman SW. Pancreatic adenocarcinoma, version 2.2014: featured updates to the NCCN guidelines. J Natl Compr Cancer Netw. 2014;12:1083-1093.

40. Abrams RA, Lowy AM, O'Reilly EM, Wolff RA, Picozzi VJ, Pisters PW. Combined modality treatment of resectable and borderline resectable pancreas cancer: expert consensus statement. Ann Surg Oncol. 2009;16(7):1751-1756.

41. Sohal DP, Walsh RM, Ramanathan RK, Khorana AA. Pancreatic adenocarcinoma: treating a systemic disease with systemic therapy. J Natl Cancer Inst. 2014;106(3):dju011.

42. Spitz FR, Abbruzzese JL, Lee JE, et al. Preoperative and postoperative chemoradiation strategies in patients treated with pancreaticoduodenectomy for adenocarcinoma of the pancreas. J Clin Oncol. 1997; 15(3):928-937.

43. Chua TC, Saxena A. Preoperative chemoradiation followed by surgical resection for resectable pancreatic cancer: a review of current results. Surg Oncol. 2011;20(4):e161-e168.

44. Bilimoria KY, Bentrem DJ, Ko CY, Stewart AK, Winchester DP, Talamonti MS. National failure to operate on early stage pancreatic cancer. Ann Surg. 2007;246(2):173-180.

45. Badiyan SN, Molitoris JK, Chuong MD, Regine WF, Kaiser A. The role of radiation therapy for pancreatic cancer in the adjuvant and neoadjuvant settings. Surg Oncol Clin N Am. 2017;26(3):431-453.

46. Crane $\mathrm{CH}$, Wolff RA, Abbruzzese JL, et al. Combining gemcitabine with radiation in pancreatic cancer: understanding important variables influencing the therapeutic index. Semin Oncol. 2001;28(3 Suppl 10): $25-33$.

47. Roland CL, Yang AD, Katz MHG, et al. Neoadjuvant therapy is associated with a reduced lymph node ratio in patients with potentially resectable pancreatic cancer. Ann Surg Oncol. 2015;22(4):1168-1175.

48. Hoffe S, Rao N, Shridhar R. Neoadjuvant vs adjuvant therapy for resectable pancreatic cancer: the evolving role of radiation. Semin Radiat Oncol. 2014;24(2):113-125.

49. University Hospital Heidelberg. Trial of Neoadjuvant Short Course IMRT Followed by Surgery and IORT for Resectable Pancreatic Cancer (NEOPANC). Available from: https://clinicaltrials.gov/ct2/show/ NCT01372735. NLM identifier: NCT01372735. Accessed August 2011. 


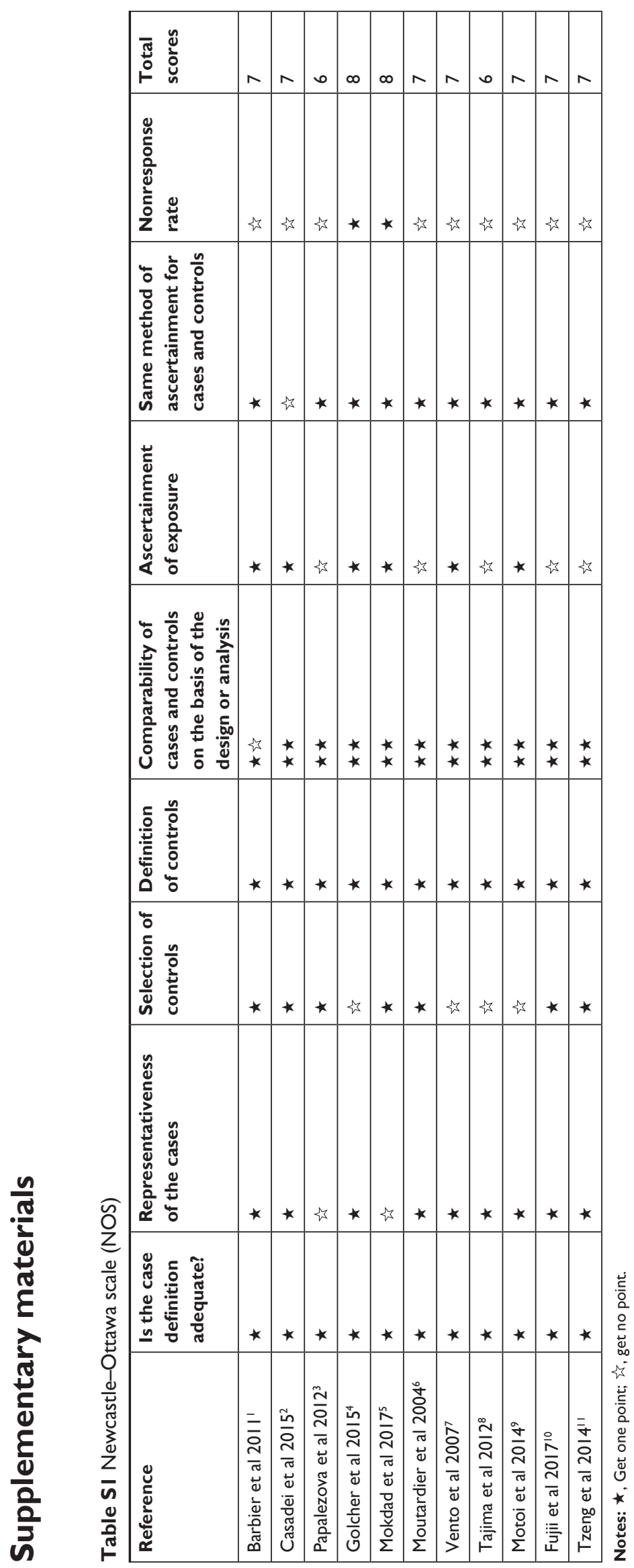


Table S2 Search strategy

\begin{tabular}{|l|}
\hline PubMed: ((pancreatic neoplasm) OR (pancreatic cancer)) AND (neoadjuvant) AND (resectable) \\
\hline Embase: (pancreatic) AND (resectable) AND (neoadjuvant) \\
\hline Web of Science: (pancreatic) AND (resectable) AND (neoadjuvant) \\
\hline Cochrane Library: (pancreatic) AND (resectable) AND (neoadjuvant) \\
\hline
\end{tabular}

\section{References}

1. Barbier L, Turrini O, Grégoire E, Viret F, Le Treut YP, Delpero JR. Pancreatic head resectable adenocarcinoma: preoperative chemoradiation improves local control but does not affect survival. HPB. 2011; 13(1):64-69.

2. Casadei R, Di Marco M, Ricci C, et al. Neoadjuvant chemoradiotherapy and surgery versus surgery alone in resectable pancreatic cancer: a singlecenter prospective, randomized, controlled trial which failed to achieve accrual targets. J Gastrointest Surg. 2015;19(10):1802-1812.

3. Papalezova KT, Tyler DS, Blazer DG, et al. Does preoperative therapy optimize outcomes in patients with resectable pancreatic cancer? J Surg Oncol. 2012;106(1):111-118.

4. Golcher H, Brunner TB, Witzigmann H, Marti L. Neoadjuvant chemoradiation therapy with gemcitabine/cisplatin and surgery versus immediate surgery in resectable pancreatic cancer: results of the first prospective randomized phase II trial. Strahlenther Onkol. 2015;191:7-16.

5. Mokdad AA, Minter RM, Zhu H, et al. Neoadjuvant therapy followed by resection versus upfront resection for resectable pancreatic cancer: a propensity score matched analysis. J Clin Oncol. 2017;35(5):515-522.

6. Moutardier V, Turrini O, Huiart L, et al. A reappraisal of preoperative chemoradiation for localized pancreatic head ductal adenocarcinoma in a 5-year single-institution experience. J Gastrointest Surg. 2004; 8(4):502-510.
7. Vento P, Mustonen H, Joensuu T, Kärkkäinen P, Kivilaakso E, Kiviluoto T. Impact of preoperative chemoradiotherapy on survival in patients with resectable pancreatic cancer. World J Gastroenterol. 2007;13(21):2945-2951.

8. Tajima H, Ohta T, Kitagawa H, et al. Pilot study of neoadjuvant chemotherapy with gemcitabine and oral S-1 for resectable pancreatic cancer. Exp Ther Med. 2012;3(5):787-792.

9. Motoi F, Unno M, Takahashi H, et al. Influence of preoperative anticancer therapy on resectability and perioperative outcomes in patients with pancreatic cancer: Project Study by the Japanese Society of Hepato-Biliary-Pancreatic Surgery. J Hepatobiliary Pancreat Sci. 2014; 21(2):148-158.

10. Fujii T, Satoi S, Yamada S, et al. Clinical benefits of neoadjuvant chemoradiotherapy for adenocarcinoma of the pancreatic head: an observational study using inverse probability of treatment weighting. J Gastroenterol. 2017;52(1):81-93.

11. Tzeng CW, Tran Cao HS, Lee JE, et al. Treatment sequencing for resectable pancreatic cancer: influence of early metastases and surgical complications on multimodality therapy completion and survival. J Gastrointest Surg. 2014;18(1):16-25.
OncoTargets and Therapy

\section{Publish your work in this journal}

OncoTargets and Therapy is an international, peer-reviewed, open access journal focusing on the pathological basis of all cancers, potential targets for therapy and treatment protocols employed to improve the management of cancer patients. The journal also focuses on the impact of management programs and new therapeutic agents and protocols on

\section{Dovepress}

patient perspectives such as quality of life, adherence and satisfaction. The manuscript management system is completely online and includes a very quick and fair peer-review system, which is all easy to use. Visit http://www.dovepress.com/testimonials.php to read real quotes from published authors. 